\title{
Water politics in Jordan: unpacking the issue and providing policy recommendations
}

Hussam Hussein (School of International Development, University of East Anglia); email: h. hussein@uea.ac.uk

Transboundary water governance in the Middle East and North Africa (MENA) region is a complex issue as it is not a mere technical problem, but it is political: it has to be contextualized in the broader geopolitical context, considering national security, regional geopolitics, inter-sectorial interests, and power asymmetries. This is particularly true when considering that the Arab region has most of its surface water originating outside of its countries, and transboundary waters represent over two thirds of its overall water resources. This policy-paper focuses on the issue of water scarcity in the case of Jordan, unfolding its roots, and providing innovative policy recommendations.

Jordan is among the three most water scarce countries in the world. Recent literature has identified the issue of water scarcity in the country as due to both the limited water resources and to mismanagement. The government emphasizes the limited water resources, underlining population growth due to immigration and waves of refugees, climate change, low precipitations, and the transboundary nature of the water resources as the main factors causing water scarcity in the country. Donors, international organizations, and NGOs, also emphasize mismanagement in the agricultural sector, leakages and non-revenue water as main reasons contributing to water scarcity in Jordan.

Given the understanding of the issue as due to the limited water resources, the solutions identified and implemented by the governments are mainly on the supply side. These solutions include exploitation of non-renewable groundwater resources from the Disi aquifer, the construction of the desalination plant within the Red Sea Dead Sea Canal project, construction of new dams, and over-exploitation of the overpumped aquifers in the country.

The decision to focus on the supply side is linked to political and social considerations, as implementing demand management strategies, tariffing systems in the agricultural sector, and reforms in the agricultural productions - which currently uses almost $60 \%$ of the water resources to produce less than $4 \%$ of the GDP, would undermine and challenge the economic interests of the farmers elites. In the Jordanian context, tribal and farmers elites are very powerful, and for the government it would be politically costly to say the least to challenge what has been often defined as the "shadow state". Given the regional political context and the priority of maintain political stability in Jordan, ensuring the support of the tribal and farmers' elites cannot be negotiated.

This paper provides policy recommendations advancing concrete and innovative solutions to government, to the international organizations, donors, and NGOs. In particular, this paper suggests combining supply and demand side solutions, instead of seeing supply-demand as a dichotomy. The solutions recommended include: awareness raising campaigns for behavioral change both at the domestic and 
in the agricultural sectors; maintenance of the water supply system through partnership with the local water utilities; stronger monitoring of water thefts through strengthening of inter-ministerial cooperation; and focus on the reuse of treated wastewater.

In addition, the Jordanian government should further support the regional dialogue and cooperation over water resources with its neighboring countries, improving transboundary water cooperation and working towards a fair and just allocation. Through innovative solutions on the regional side, Jordan should lead the way towards creative and win-win solutions looking out of the water-box, considering inter-sectorial interests, including energy, food production, and tourism. Jordan should renegotiate and call for new basin agreements on the Jordan River and on the Yarmouk River, with the goal of increasing water resources, rehabilitating the Jordan River, consequently saving the Dead Sea and the biodiversity of the basin, and ensuring stability in the region. The agreements should be fair to all countries involved, and follow principles of international humanitarian law and UN international water conventions. 